\title{
Tibial Adamantinoma
}

National Cancer Institute

\section{Source}

National Cancer Institute. Tibial Adamantinoma. NCI Thesaurus. Code C8461.

An adamantinoma arising from the tibia. The tibia is the site which is more frequently involved by adamantinoma (80-90\% of cases). 